The following cases have been operated on in this way:

\begin{tabular}{|c|c|c|c|c|c|}
\hline \multicolumn{6}{|c|}{ CASES TREATED } \\
\hline F. J., & Nov. & 1894 & Gyn. & No. & 7351 \\
\hline S. S., & Nov. 14, & 1899, & & & 7370 \\
\hline E. J., & Nov. 14 , & 1899 & " & " & 7371 \\
\hline S. T., & Nov. 18, & 1899, & “ & “ & 7384 \\
\hline E. M., & Nov. 29 & 1899, & $\because$ & “ & 7405 \\
\hline К.H., & Nov. 30 , & 1899 & “ & “ & 7411 \\
\hline M.J., & Dec. 2I, & 1899 & “ & " & 7428 \\
\hline M.H., & Jan. 10, & 1900 & “ & “ & 7495 \\
\hline I. B., & Feb. 24, & 1900 & “ & “ & 7582 \\
\hline C. H., & Mch. 28, & 1900 , & " & “ & 7674 \\
\hline M.W & Apr. $\quad 2$, & $\begin{array}{l}1900, \\
\text { Il reco }\end{array}$ & " & “ & 7564 \\
\hline
\end{tabular}

I have frankly and without reservation put before you all my own work and my own thoughts on this subject, and I shall be abundantly rewarded if $I$ succeed in inducing some of those present to express their views and throw some light from their large experiences on what is still one of the darkest chapters in surgery.

1414-1418 Eutaw Place.

DIscussron.

Dr. Henry C. Cor said that he had met with much disappointment when doing the old operation of skinning out the uterus. He believes the radical operation of the future will be an abdominal hysterectomy, as this is the most scientific cutting operation known to-day. The great difficulty is to decide, at the time of operation, between simple inflammatory tissue, and that the seat of malignant degeneration. Dr. Byrne's method of treatment by the application of the electrocautery seemed thoroughly rational, and more than this, is supported by a series of brilliant results achieved by Dr. Byrne himself. Regarding the mode of extension, he does not feel sure that cancer of the uterus always extends by continuity. For example, when the radical removal of a small circumscribed malignant adenoma by abdominal hysterectomy is quickly followed by recurrence in the scar, the explanation, on that basis, is difficult.

Dr. Egrert H. Grandin spoke of his personal experience with cancer of the uterus. Although that with the diseases of women has been large, he has seen comparatively few cases of carcinoma uteri-only 48 . In 30 of these the bladder, rectum and broad ligaments were involved, and he did not feel justified in resorting to a major operation; he is disposed to believe that, in these advanced cases, the less done the better. Of the 48 cases, 18 were suitable for operation. For carcinoma of the body, total hysterectomy has been the operation of election, and was done in 12. He has been able to trace 7 of these, and has found them free from recurrence. The longest time since operation in these is six years. Vaginal hysterec tomy was done on 6 patients in whom the portio vaginalis was implicated, and of the 4 he has been able to follow up, only 1 has remained free from recurrence. 'Vaginal hysterectomy, whether by clamp or ligature, should be rejected in cases of cancer of the uterus, because more thorough work can be done by the abdominal route. The method of the future will probably be a combination of knife and cautery.

Dr. William R. Pryor expressed himself as opposed to the vaginal operation for these cases, nor does he look favorably on Dr. Kelly's method of doing morcellement by the vaginal route in cases of cancer of the cervix. Vaginal hysterectomy is little better than a palliative operation, yet it is attended by a mortality of from 5 to 10 per cent. His preference is for abdominal hysterectomy, and hemostasis by the ligation of the internal iliac arteries.

DR. P. H. Ingalls, of Hartford, Conn., said that most of the cases coming to him were far advanced. A partial operation, as with the cautery, seems to him to rather aggravate than alleviate the condition. Operations for cancer of the body have done better in his hands than those for cancer of the cervix.

(To be continued.)

\section{CLEFT PALATE.}

\section{A NEW URANO-STAPHYLORRHAPHY.} BY ALEXANDER HUGH FERGUSON, M.D.

\author{
Professor of Surgery, Chicago Post-Graduate Medical School \\ Surgeon-in-Chief, Chicago Hospital. \\ CHICAGO. \\ STAPHYLORRHAPHY.
}

In 1764 a French dentist, named Le Monier, proposed for the first time to close the cleft in the soft palate by paring the edges and stitching them together, which was successfully carried out by the elder Roux of Paris in 1819. In 1820, Warren of Boston, and independently of Roux, brought before the profession a similar but somewhat better operation, which he had successfully performed. So closely do the two resemble each other in principle and technique that it might well be called the Roux-Warren staphylorrhaphy. This operation was followed by the best surgeons of that time, for about a quarter of a century by such men as Stevens of New York, Mettauer of Virginia, Wells of South Carolina,

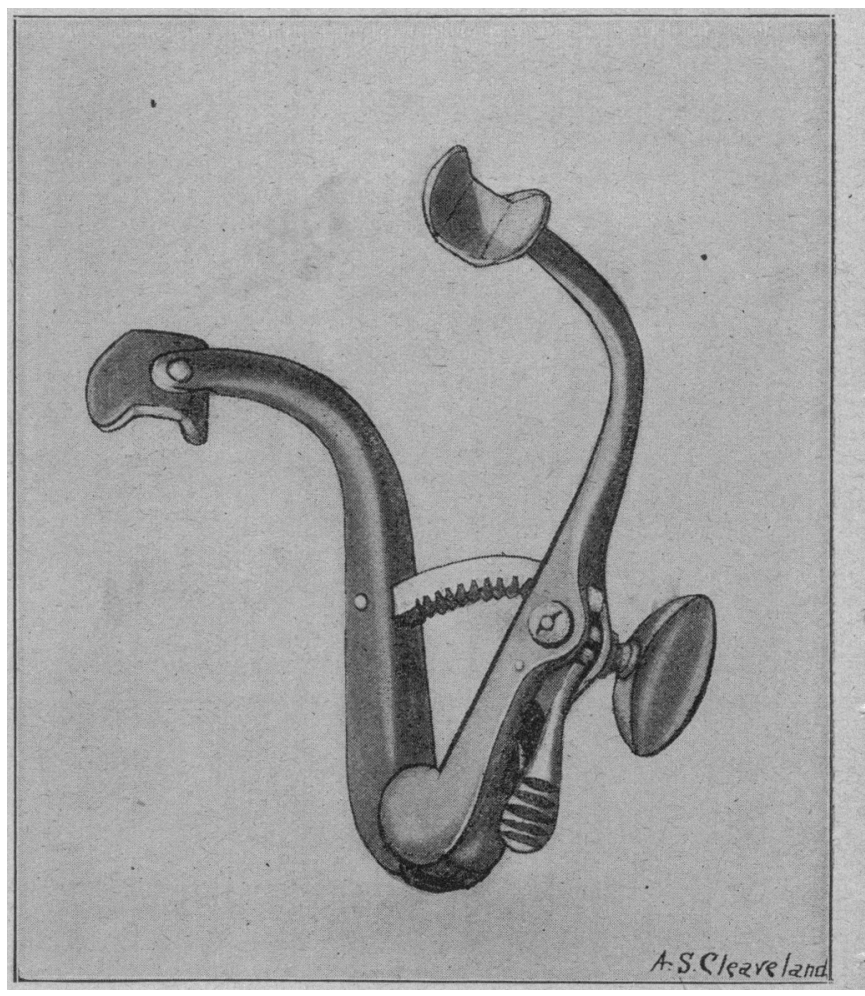

Fig. 1. - Month Gag.

Gibson of Philadelphia, Hossack, the younger Warren, Mütter, and Pancoast in this country. Among the surgeons abroad who performed this operation may be mentioned Graefe, Dieffenbach, Sédillot, Liston, Fergusson and Polloch. Fifty-six years ago Sir William Fergusson of London made the first marked improvement on the simple vivification and suture operation. He recognized that the tension on the ligatures was a great cause of failure, and decided that this tension was due to the contraction of the levator palati, palatopharyngei and palatoglossi muscles. To relieve this tension he divided these on either side. He devised a hoe-shaped knife, with which he severed the levator palati muscles by passing it behind the soft palate and cutting from behind forward. In this connection Fergusson was the first to make careful dissections of cleft palates on cadavers. The excellent results obtained by him were also secured by other surgeons who had followed him. His operation super- 
seded the Roux-Warren one for several years. The next improvement recorded was in 1860 , by Dr. Agnew, of Philadelphia, who pointed out that the tension of the soft palate is in a measure dependent on the contraction of the tensor palati muscles, and these he cut by making an anterior incision close to the hamular process of the sphenoid bone, and thereby obtained marked relaxation. About the same time Dr. Polloch of London carried.out a similar procedure. From the ease with which the anterior incision could be made and the fact that it eut the lowermost fibers of the levator palati muscles as well, it soon became a favorite. With the exception of a flap-splitting of the soft palate, carried out by many surgeons, nothing new appeared on this subject until Dr. T. W. Brophy, of Chicago, introduced the application of lead plates to the soft palate, which bear the strain of the sutures, thus preventing muscular contractility and tension. He finds it unnecessary to cut the muscles on either side, and maintains that it is harmful to sever them.

URANOPIASTY.

Staphylorrhaphy was an established procedure in surgery before the closure of the cleft in the hard palate was attempted. Before fifty-seven years ago obdurators were freely used. Dr. J. Mason Warren, of Boston, in 1843,

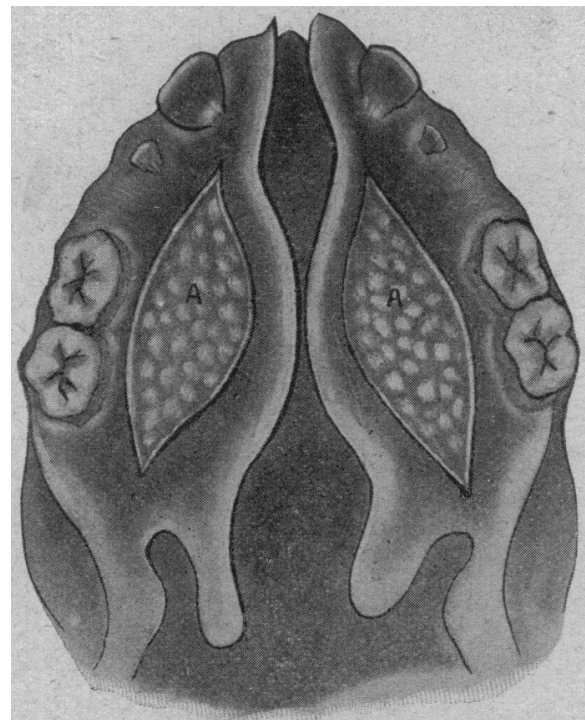

Fiz. 2.-Crowding procedure for a wide cleft. A, A, gauze crowding the muco periosteal flaps toward the center.

published his method, which consisted in paring away the mucous membrane of each side, raising the flaps of mucous membrane from the bones and suturing them together. Langenbeck effected an improvement by raising the periosteum with the flaps and by making two lateral incisions, one along each alveolar process. In $1873 \mathrm{Sir}$ William Fergusson came on the scene again with his ingenious osteotomy of the hard palate in its entirety, pared the edges of the segments of both hard and soft palate, and brought them together at one sitting, thus completing his urano-staphylorrhaphy. Mason, in 1874, suggested some slight improvements in Fergusson's operation. Garretson of Philadelphia applied to the jaws a horseshoe-shaped clamp, and with it forced the jaws together by means of a screw similar to that of Hainsby. Billroth frequently crushed the hamular processes together, and Wolff utilizes the alveolar processes to close the cleft. Lannelongue constructed a flap, in unilateral cases, from the mucous membrane of the contiguous surface of the nasal septum.

The Davies-Colley method I have performed a good many times, and like it very much. The cleft is bridged across by means of two flaps. One flap is raised laterally, its outer border being free, while it is left attached at the margin of the cleft. It is then turned upward into the cleft, its mucous surface looking toward the nasal cavity. The flap on the other side is raised like a tongue, its anterior end being free, and is brought across to the opposite side underneath the first flap, raw surface to raw surface, and there fastened with a few sutures. It is an excellent plastic operation.

Brophy's Method (Park's Surgery).-This consists in forcing the two superior maxillæ together with stout silver wire fastened to a lead plate, one placed on the outside of each alveolar process. The approximation is effected by twisting the wire over one of the lead plates. The usual vivification of the segments is made, and sutures applied in the ordinary manner. In infants this operation is feasible. Its author claims but little shock, and excellent results. C. B. Porter, when patients have teeth, uses a vulcanite plate in the mouth to protect the soft palate (Warren-Gould's Surgery, Vol. ii,

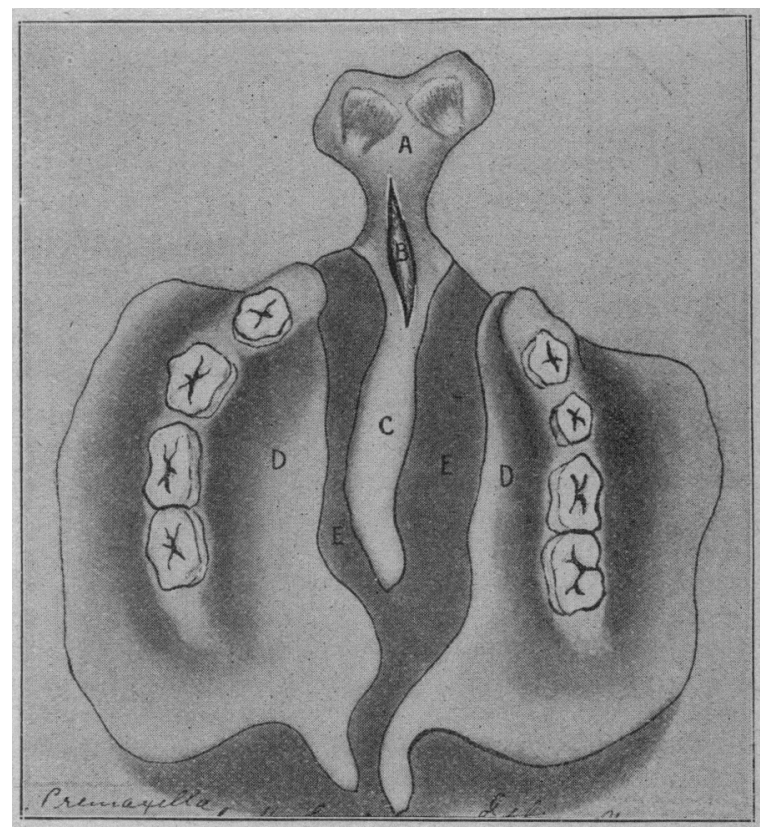

Fig. 3.-Oz incisivum. A, premaxilla: $b$, incision to the bone; $d, d$, segments; $\theta$, $\theta$, clefts; c, ethmo-vomerine septum.

p. 26). Fillebrown makes an incision along the alveolar processes, raises two muco-periosteal flaps, turns them toward the center of the cleft, and there fastens them together with mattress sutures of silver wire, the edges being vivified and sutured with fine silk.

Instruments.-The only new instrument I wish to present is a mouth-gag (Fig. I), which I devised and find suitable for all cases. It is small, strong, opens widely, is easily inserted into the mouth, quickly closes, does not strike against the shoulder and lies close to the cheek.

Preparation of Fatient.-Adenoids, enlarged tonsils, nasal catarrh, bronchitis, malnutrition, etc., should be treated first. The child should be in the best attainable condition locally and constitutionally before an operation is advised. The day before the operation a dose of castor-oil and a few doses of strychnia should be administered. Irritating the month with antiseptic lotions for several days previously is contraindicated.

A ge.-In my opinion, all operative procedures on harelip and cleft palate should be completed before the 
child begins to talk. The earlier the congenital deform ity of the palate is rectified, the less defective will be the speech. In infants a few weeks old the mouth is small, the tissues are friable, and there is a tendency for the flaps to slough. Should the cleft be wider than half an inch, the complete closure of it is not undertaken at the first sitting, but one or more crowding operations can be done to lessen it. (Fig. II.) In this case Langenbeck incisions are made, and iodoform gauze firmly packed into the wounds and beneath the muco-periosteal fiaps in such a manner as to crowd them toward the center until they touch. When this is properly done the gauze will remain in place for a week or more. It is not removed until it begins to loosen, after which a second packing may be inserted, but usually this is not necessary, for the new granulation tissue is sufficient to hold the soft structures in their altered positions. Three or four weeks should now elapse before operating again. The palate bones are allowed to become covered over with firm fibrous tissue segments. 'The crowding operation is most suitable in a class of cases otherwise very difficult to treat, that is, when the segments are horizon-

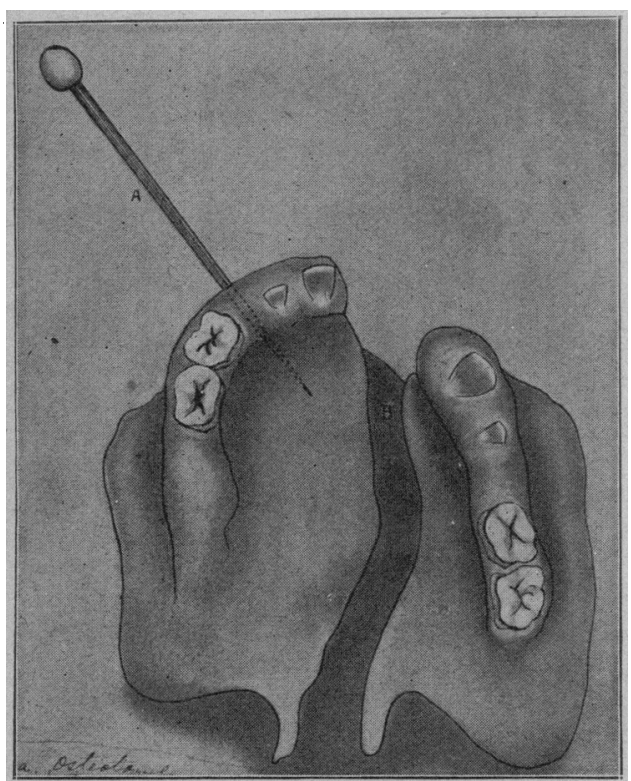
gide.

Fig. 4.-Supra-maxillary osteotomy. A, osteotome; b, cleft on one

tal, and the roof is like a Norman rather than a Gothic arch. The flaps in this class of cases are shorter, and by the older methods great traction is employed to bring the pared edges in apposition, hence the frequent cause of failure. When the bony edge of each segment is not well covered by mucous membrane, even though the cleft is narrow, a crowding operation is done as preparatory to the final closure of the cleft in order to obtain flaps sufficiently thick and well nourished to insure success. The more vertical the slope of the palatal segments, the more favorable the case is for operation by old methods.

Os Incisivum and Harelip.-'The os incisivum, also called the premaxilla and intermaxilla, protrudes in the center in double harelip, and in single it often protrudes to one side, where it is attached, thus raising the nostril on that side far above the level of its fellow. This de. formity has been dealt with in various ways. When met with in infants it is my practice to deal with it before operating on the cleft palate, but in older cases nothing is gained thereby, and then I repair the palate first. When possible, the intermaxillary bone is preserved. A V- shaped section is lemoved from the vomer subperiosteally (Fig. III), through a longitudinal incision, the bone nicely fitted in between the superior maxillæ, and held there by means of a strong silver wire, taking care to pare off the edges on each side so as to obtain bony union if possible. If, however, the harelip operation is

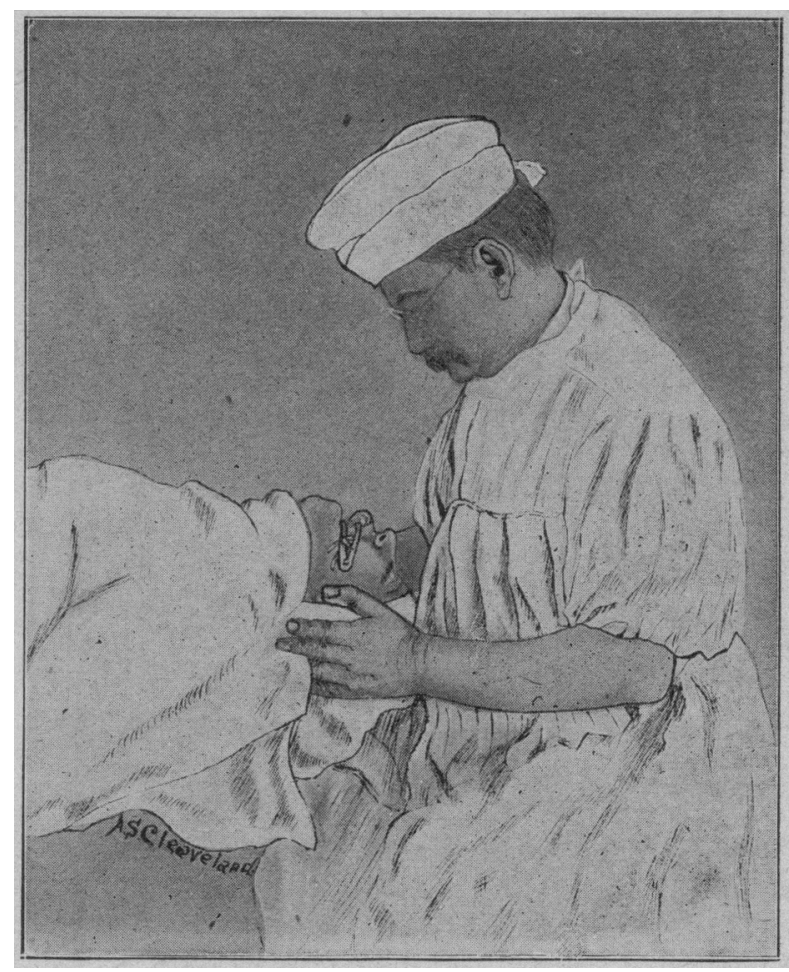

Fig. 5.-Position of surgeon and patient.

done early, it may not be neeessary to perform any operation on the vomer, for in some cases it will be found that the os incisivum has receded to nearly its normal position. When the deformity is one-sided, it is easier to lower one nostril than to raise the other. This is done

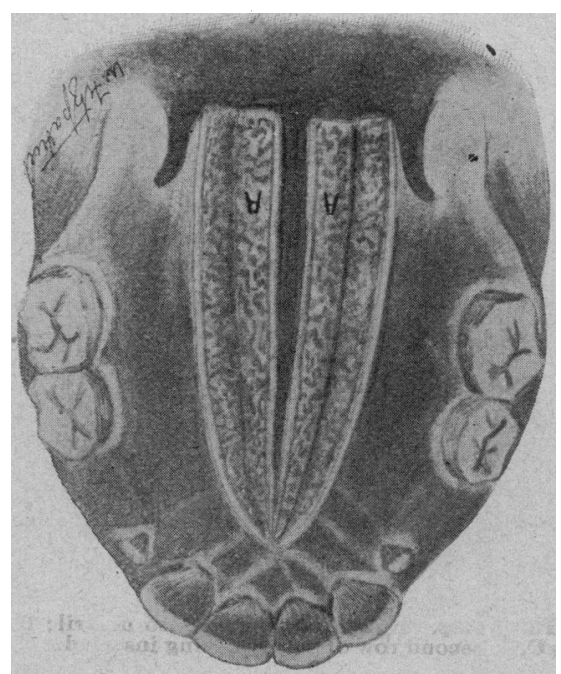

Fig. 6.-First step.-A, A, flaps hinged by the mucus membrane on the nasal aspect.

by making a supramaxillary osteotomy, as represented in Fig. IV. Here, too, when the harelip is closed in the infant, the deformity is greatly improved and the osteotomy may be obviated. In the development of the child the union of these bones naturally takes place from before backward, so that by repairing the harelip and wait- 
ing a few months the alveolar cleft is very much lessened.

Ethmovomerine Septum.--The ethmovomerine septum is frequently very deficient or entirely absent. When present it materially facilitates the execution of plastic work in the roof of the mouth, by utilizing its mucous membrane.

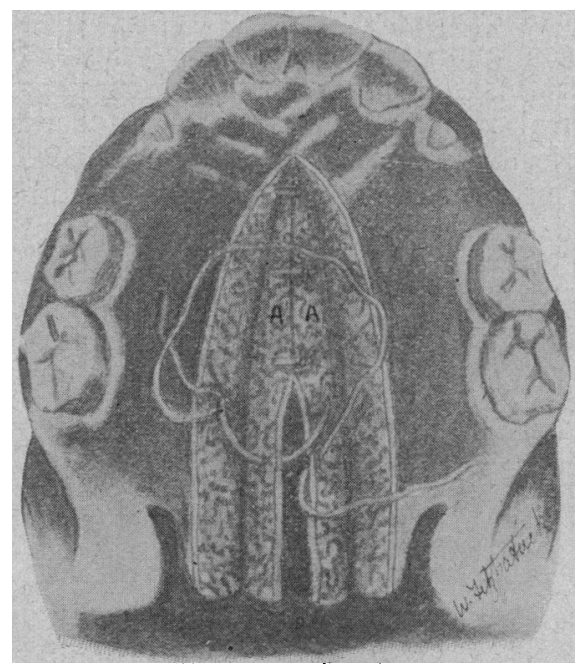

Fig. 7.-Second step.-A, A, flaps coapted by three sutures and fourth one being inserted.

\section{A NEW URANO-STAPHYLORRHAPHY.}

The operation which I now wish to describe has been carefully studied and practically developed. It was done on fifty-three patients, extending over a period of eleven years. In 1889 I successfully performed it on three sisters. In one the defect extended through the soft palate alone, and in the other two the hard palate was involved, but not the alveolar process. Since then I have managed to prepare my patients so that finally in nearly all of them I could perform my operation, resorting to the crowding operation to this end.

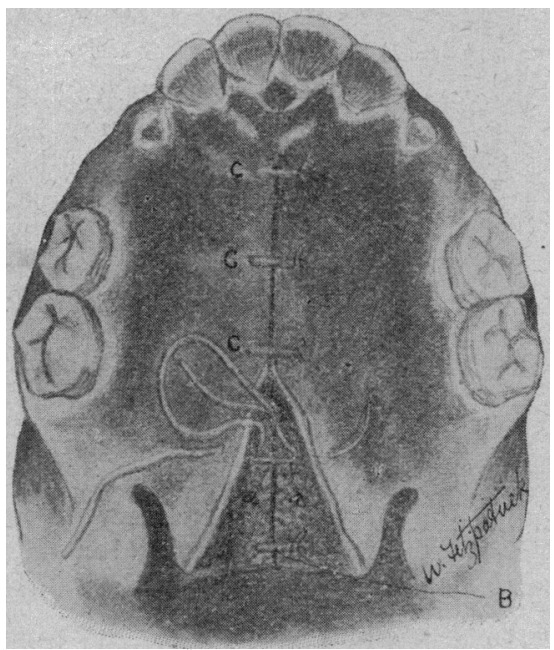

Fig. 8. -Third step.-a, a, flaps inserted into nostril; B, last stitch of first row: C, C, C, second row of sutures being inserted.

Wrap the child in a sterile sheet with its arms extended along its sides; fasten a towel wrung out of a bichlorid solution around the head, or put on a rubber cap; place it on a table with a headpiece that can be raised or lowered; administer chloroform drop by drop; mop its face, mouth and throat with equal parts of alcohol and water: with a 4 per cent. cocain solution on cotton, touch the palate and pharynx; if secretion is profuse, give a hypodermic of atropia, the dose to suit the age of the patient; insert the mouth-gag; sit at the end of the operating-table, with the patient's head well thrown back (Fig. V), and you are ready for work.

The anesthetizer has a difficult task to keep the patient well under the influence of the chloroform, and also allow the surgeon sufficient time to work. It necessitates a wide range of the degree of nareosis, thus coming to and going under alternately, but this fluctuation in the administration of the chloroform is much safer than keeping the patient constantly in a state of surgical anesthesia by spraying the chloroform through a nostril.

1. Making the Flaps.--With a slender, slightly curved, narrow-bladed knife, cut through the mucous membrane of the mouth about one-sixteenth inch from the edge of each segment, and divide all the soft structures to the mucous membrane on the nasal aspect of the palate, but not through it. (Fig. VI.)

2. First Row of Sutures.-With a small, round, fully curved needle, not larger than one-half inch between the eye and the point, held in a suitable needleholder, and threaded with fine silk, closely insert inter-

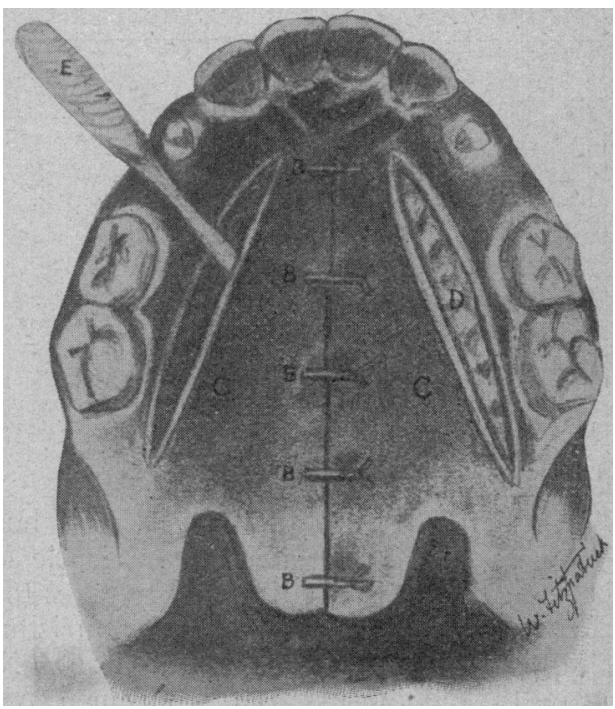

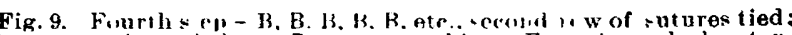
C, C, mucu periest..-al tiaps: D, wauz-. packing; F. periesileal elevator

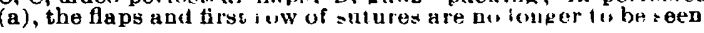

rupted sutures by passing the needle through the free borders of the flaps from the mucous surface to the raw, and from the raw to the mucous surface, and tie them as you proceed from before backward, all the knots being situated on the nasal side. (Fig. VII.)

3. Second Row of Sutures.-Take the same needle and needle-holder and complete a row of interrupted stitches of horsehair on the buccal surface of the palate from the tip of the uvula forward, and tie them where apposition is possible without tension. The soft structures of the hard palate can not usually be brought together until the next step of the operation is taken. (Fig. VIII.)

4. Muco-Periosteal Flaps.-Place the forefinger of the left hand on the hamular process; take a short, strong, slightly curved, narrow-bladed knife, and make a curvilinear incision on one side, beginning just behind the hamular process, cutting down to the bone and extending forward along the alveolar process, as far as desired; prevent hemorrhage by pressure with the finger and gauze; rapidly raise the muco-periosteal flap, with a strong periosteal elevator, from the segments of the hard palate, and immediately pack the wound firmly 
with iodoform gauze. Repeat this performance on the opposite side, and tie the horsehair stitches not already secured. The soft structures of the hard and soft palate are beautifully held in apposition without tension on the stitches. (Fig. IX.)

In packing the iodoform gauze in the wounds, fixation points are obtained by forcing some of it into the bone, also between the teeth and under the mucous membrane. If this is properly carried out, the gauze will remain in place for a week, and sometimes longer. It is nemoved when it becomes loosened, by which time it has generally fulfilled its usefulness. A second and occasionally a third packing may have to be inserted.

It will be observed that this is not a flap-splitting but a flap-formation operation, the flaps carrying with them two narrow strips of the firm, strong, buccal mucous membrane of the palate, which holds sutures securely, and when they are turned upward and held in coaptation by means of the first row of sutures they form an ideal protecting roof to the raw surfaces beneath them, and afford twice the width of denuded tissues for apposition, and the nasal mucopurulent discharge is shed off to either side. (Fig. X.)

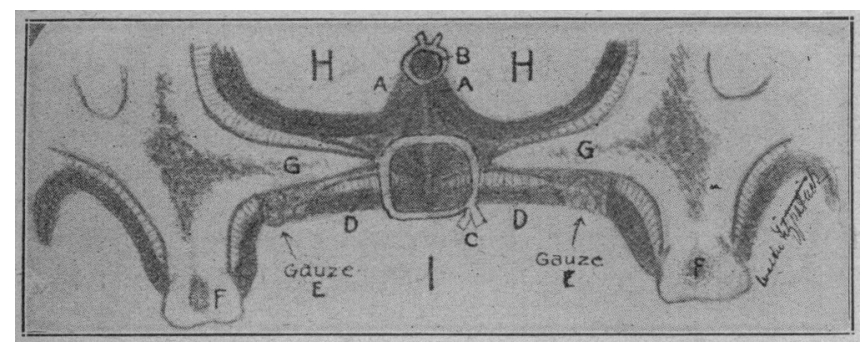

Fig. 10.-Supposed transverse section when operation is finished, A. A, flaps made and turned into nostril ; B, first row of sutures: C, second row of sutures; D, muco-periosteal flaps cospted by $C ; E, E$, gauze; F. Garth; G, Segments of bone (palate); H, H, nasal cavities; I, mouth.

After-Treatment.-Every two or three hours the mouth is to be cleansed with a feeble antiseptic solution, such as boric acid, etc. The child readily takes to whisky and water, which is given after taking nourishment, to wash the liquid food off the area operated on. Nutrient enemata are to be administered if deemed necessary, and the stitches removed not earlier than the twelfth day. If the patient cries much, we should keep it quiet with an opiate. A special nurse, experienced in caring for cases of this nature, should be employed.

Cases Suitable for the Operation.-1. The cleft in the hard palate must not be wider than half an inch, but if it is, a preparatory crowding operation is done first. 2 . The mucous membrane covering the inner edge of each bony segment should be thick and well nourished; if not, the crowding operation is resorted to primarily. 3. It is suitable for all clefts in the soft palate.

Commendable freatures.-1. The results are vastly better than I have been able to obtain by any other method. I have had only one primary failure. 2. No tissue is removed. 3. Very broad raw surfaces are coapted. 4. The danger from sepsis is minimized by turning the flaps upward, as described.

Disadvantage. - It is more difficult to perform.

ONE of the features of the Paris daily, the Figaro, is a column each week devoted to a summary of the leading articles in the principal medical journals. It is written over a pseudonym by $\mathbf{M}$. de Fleury, a well-known physician and contributor to medical literature, and presents, in popular style, the latest medical achievements.

\section{A CASE OF HYSTERICAL HIP-JOINT.}

\section{BY JOHN LINCOLN PORTER, M.D.}

Instructor of Orthopedic Surgery, College of Physicians and Surgeons.

\section{CHICAGO.}

Miss E. H., a schoolgirl, 11 years old, came under observation Jan. 24, 1898, with the following history: She had had measles, chicken-pox and whooping-cough in childhood, and scarlet fever three years before $I$ saw her. After this she had severe headaches, pain in the upper dorsal region and "trouble with her stomach." The gastric disturbance consisted of attacks or crises, occurring at quite regular intervals of about a month, with headache, eructations, sometimes vomiting, and pain of an intermittent character in the abdomen; and

\section{.}

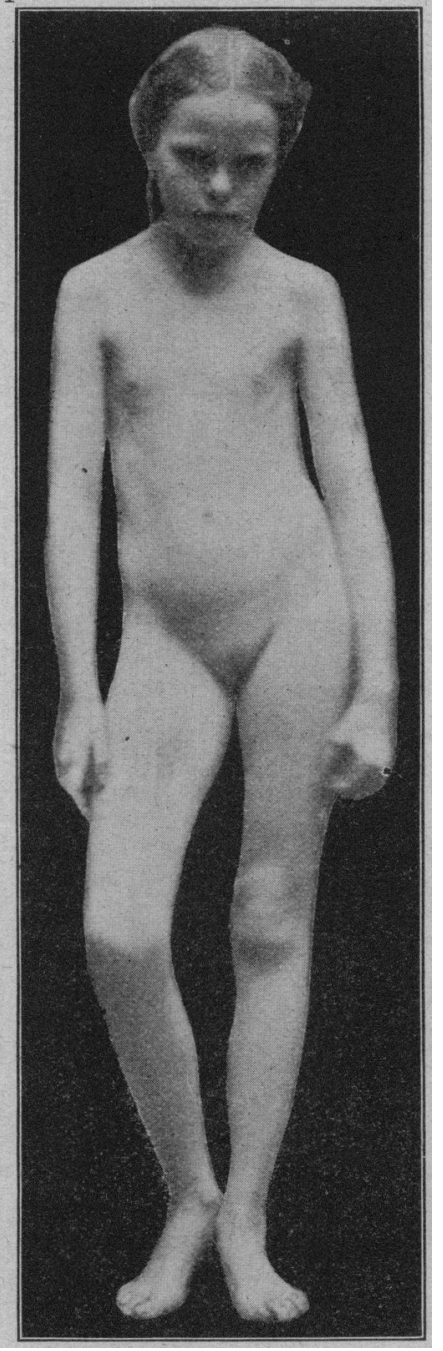

Figure 1. with this was extreme nervousness amounting at times to nervous storms. These attiacks lasted for two or three days, and rapidly passed off, leaving the patient in good health. She had never menstruated. In September, 1897, she began to complain of pain in the right hip, and these pains recurred, with intervals of perfectcomfort, for six months; then a slight limp developed, which had been gradually getting worse, though she had been up and about as usual all the time.

Family Eistory: There was no history of tuberculosis, syphilis or insanity in either branch of the family as far back as, and including, the grandparents. Both parents wereliving, also five other children, all of whom were in apparent good health. The mother and her four sisters were all of very nervous temperament and subject to severe headaches.

Condition on Examination.-The patient was a red-haired, blond girl of fairly good development for a girl of

11 years, and apparently anemic. She had large, full eyes, with a restless expression, was alert and quickmotioned, looked at every one and all approaches with suspicion, and clung to her mother in a timid manner. She would not talk, but answered direct questions with a shake or nod of her head. Her standing position and gait at once attracted attention (Figs. 1 and 2), for she stood with the right thigh flexed and rotated outward, and only the toes touching the floor. In walking the same position was maintained, the weight being carried on the toes, but the flexion increased each time the weight was borne by the right leg. On inspection, the affected hip and leg seemed perfectly normal, there be- 